\title{
Editorial:
}

\section{Human Resource Management and Economic Success}

Human resource management has long been perceived as an "ugly duckling" within the wider field of business administration. The perception's roots are manifold. A critical issue, however, has always been that the utility of human resource management to a company's business success has been insufficiently demonstrated. In contrast to other business sub disciplines with deeper roots in classical micro-economic theories of the organization, human resource management could not acquire legitimacy through connectivity to production or sales functions. Although human resource management's practical utility has long been assumed, it requires empirical demonstration.

Empirical evidence of an association between human resource management and company economic success has proved difficult. As long as human resource management has not been seen as a coherent pattern or system - in contrast to individual HR practices or loosely tied bundles of instruments - performance may only be ascribed to the specific effects of single instruments or measures. An example is increased employee satisfaction as a result of particular leadership styles, improved motivation due to different compensation packages or work tasks, decreased employee turnover because of enhanced selection procedures, etc. These empirical arguments may be of great interest within the particular field of research, but they do not satisfy, for example, economists. Only the development and implementation of coherent patterns or systems of human resource management practices - following HR's struggle for a strategic orientation - will ensure that the discipline of human resource management faces other sub disciplines on equal terms. Henceforth, proof of single HR instruments' relevance moved from the centre of attention, giving way to examination of the functionality of selected human resource systems for a company's economic success.

This change in perspective - from the efficiency and effectiveness of specific instruments to the contribution of human resource management as a whole on an organizational level - has required different data sets than hitherto. Institutions rather than employees are the subject under analysis. In the European context, the Cranfield Network on International Human Resource Management (Cranet) provides longitudinal data on the organisational level since 1989. This dataset allowed, for the first time in Europe, analysis of the association of selected systems of human resource management practices (empirically identifiable as bundles/clusters of human resource measures) with a company's economic success. Cranet, starting with five European countries in 1989, now allows comparative international analysis of 39 (mostly European but also selected non-European) countries.

As is often the case when looking at evidence-based research, audience receptivity is more important than advances in theoretical and empirical instruments. In this specific case - as hypothesized by the guest editors - company demand for human resource management has risen. The attraction, development, and retention of specific human capital has moved decisively to centre stage. In short, it is obvious that in the 
age of post-fordism, human resource management is a major focus of attention for practitioners as well as academics.

This issue presents results from an international symposium organised by the guest editors in February 2004 to honour Wolfgang Weber's academic work on the occasion of his $65^{\text {th }}$ birthday. Wolfgang Weber's work has been intimately connected with the discipline's strategic orientation as well as comparative international human resource management's organization and institutional anchoring. It is to our great pleasure that in total eight out of fourteen manuscripts successfully passed through the review process for this special issue, generating a considerable contribution to the research field.

Following the standard procedure for each special issue of Management Revue, the first contributions attempt a critical overview of the state-of-the-art, and are followed by empirical studies addressing selected issues exploring the link between human resource management and economic success.

In the first article, Patrick Wright and John Haggerty look at missing variables in theories of strategic human resource management. They argue that much progress has been made in the last decade with regard to theory building and application in the field. While researchers have increasingly analysed human resource management's impact on economic success within the resource based view of the firm, and have developed more meso-level theories, much work remains to be done. The authors examine how future theorizing needs to explore the relevance of time, causation, and the role of individuals.

Barry Gerhart reviews empirical findings on the link between human resource management and economic success, identifying unanswered questions and suggesting an alternative analytical approach. He calls for researchers to allow more confidence in the validity of their findings, and for them to spell out implications for practice. Instead of defining human resources in terms of HR practices reported by a single managerial respondent, the author suggests studying employee relations as measured by an employee survey.

Eleni Stavrou and Chris Brewster examine the link between human resource management and economic success from a configurational perspective. Utilizing the Cranet European data, the authors first identify unique bundles of human resource practices and then analyze the extent to which these bundles are linked to business performance. The study suggests that successful European enterprises seem to be converging towards utilizing strategic human resource management as a competitive tool involving selected bundles of human resource practices.

Peter Dowling examines the link between human resource management and economic success in an Australian context from a business systems approach. Describing the specificities of the Australian business environment and the consequences for human resource management, the author adopts an international comparative lens, arguing that there is evidence both for and against universal prescriptions for effective human resource management.

Fernando Martín Alcázar, Pedro Miguel Romero Fernández, and Gonzalo Sánchez. Gardey conducted an empirical study asking 220 human resource management scholars for 
their perceptions of the state of the art and the development of the HR/economic success field. The authors suggest four research perspectives representing different modes of theorizing: universalistic, contingent, configurational, and contextual. Despite the evident differences between these four perspectives, the authors observe complementarities and argue for an integrative perspective that develops multidisciplinary, multi-paradigmatic and multidimensional frameworks in order to enrich our understandings.

Justine Horgan and Peter Müblau examine whether high performance human resource systems affect employee and company performance in Ireland and the Netherlands. They argue that these systems' effectiveness is shaped by a 'societal effect'. Different countries' skill formation, industrial relations and value systems support or discourage the mobilization of employee performance. Empirical results from a postal survey of establishments show high-performance human resource management exercising a substantial effect on employee performance and indirectly on economic performance of companies in Ireland but not in the Netherlands. Moreover, the empirical results suggest that the impact of high performance human resource management is weaker in the Netherlands than in Ireland. Examination of single HR domains shows that incentives, structuring, selection efforts and sharing arrangements were more strongly associated with employee performance in Ireland than the Netherlands, underlining the relevance of the societal effect.

Seong-Kook Kim and Ji-Sook Hong examine the association between salespersons' competencies and performance in the Korean pharmaceutical industry. Based on analyses of 457 salespersons and managers from 5 different pharmaceutical companies in South Korea, the authors show that the level of salesperson competencies is positively related to individual performance. They also show that the quality of leadermember exchange positively influences the relationship between competencies and performance, underlining the importance of leadership in competency models.

Sbimon Dolan, Mercè Mach, and Vincenta Sierra use firm level analysis when examining the link between human resource management and economic success. Their empirical study, based on Spanish Cranet data, is presented in two stages. In a first stage, economic/financial measures from external data sources are used to supplement the Cranet data set. These objective measures for economic success at the firm level are aggregated into two groups (productivity of work and financial performance). In a second stage, the authors analyse selected bundles of human resource practices and the extent of their contribution to performance criteria.

In Hans Christian Anderson's tale, the "ugly duckling" was different from the others, but eventually emerged as a "beautiful swan". Might this, due to HRM's unique nature, be analagous to human resource management? If HR perceives itself as more than a residual function, then it must prove its contribution to firm performance. Our swan had to learn how to swim as did the ducklings. We think it is beginning to turn out well. 